\title{
Transplante lobar experimental em suínos: enxerto proporcional na disparidade entre receptor e doador*
}

\author{
Nuno Ferreira de Lima², Oliver A. Binns², Scott A. BuChanan², \\ Kimberly S. ShOCHEY ${ }^{2}$, CURTIS G. TRIBBLE 2 , IRVING L. KRON²
}

\begin{abstract}
Objetivo - Perante a crítica falta de orgãos disponíveis para transplante, a doação intervivos de lobos ou segmentos pulmonares é possível e necessária no transplante pulmonar pediátrico. Na grande disparidade de tamanho do doador adulto e a criança pequena receptora, o lobo médio ou segmento pulmonar representa um enxerto de restrito leito vascular. Este estudo experimental testa a hipótese de que esse tipo de enxerto pode desenvolver hipertensão pulmonar no animal receptor, ao final do período de crescimento. Métodos - Foi utilizado um modelo de sobrevivência de transplante pulmonar à esquerda em leitões. Constituíram-se três grupos de comparação: I $(n=4)$ - transplante de lobo superior de doador adulto, enxerto proporcional ao receptor, mas

irrigado por apenas dois ramos arteriais; II $(n=5)$ - transplante de lobo inferior de doador adulto, enxerto desproporcional ao receptor e com amplo leito vascular; III $(n=6)$ - transplante de pulmão imaturo de leitão doador proporcionado. Os animais transplantados tiveram a função do enxerto pulmonar estudada ao final de 3 meses, quando completaram o período de crescimento. Resultados - A pressão da artéria pulmonar do enxerto do grupo I $(51,8 \pm 2,1 \mathrm{mmH} \mathrm{g})$ foi mais elevada do que no grupo II $(40,4 \pm 2,5 \mathrm{mmH}$ g) e do que no grupo III $(34,8$ $\pm 1,5 \mathrm{mmH} \mathrm{g}$ ), atingindo significância estatística $(p=0,0003)$. Conclusões - 0 enxerto lobar proporcional ao

receptor, mas de leito vascular restrito, teve desempenho hemodinâmico comprometido no animal em crescimento. Esses dados sugerem que a proporcionalidade do enxerto não deve ser prioritária e, antes, ser secundária a um adequado leito vascular do enxerto. (J Pneumol 1999;25(2):63-69)
\end{abstract}

\section{Experimental lobar transplantation in swine: proportional graft in the discrepancy between donor and recipient}

Background - The critical donor shortage in pediatric pulmonary transplantation has prompted lobar transplantation from living-related. However, in the case of great size discrepancy between the adult donor and the small child recipient, a pulmonary segment or medium lobe represents grafts with restricted vascular bed. The authors hypothesized that this type of graft may develop pulmonary hypertension in the recipient by the end of the growth period. Methods - This hypothesis was investigated in a porcine survival model of lung transplantation in piglets. There were three groups for comparison purposes: I $(n=4)$ transplantation of the upper lobe from an adult donor, graft being proportional to the recipient but irrigated by two arterial rami only; II $(n=5)$ - transplantation of the lower lobe from an adult donor, graft being oversized to the recipient and having adequate vascular bed; III $(n=6)$ - transplantation of immature lung, from matched-sized donor. Graft function was studied three months after the transplantation, when the growth period was completed. Results - The pulmonary artery pressure of grafts in group I (51.8 \pm 2.1 $\mathrm{mmHg}$ ) was increased compared to that of group II $(40.4 \pm 2.5 \mathrm{mmHg})$ and of group III (34.8 $\pm 1.5 \mathrm{mmHg})$, reaching statistical significance $(p=0.0003)$. Conclusions - The lobar graft proportional to the recipient, with restricted vascular bed, had hampered hemodynamic performance in the growing animal. These results suggest that graft proportionality should be secondary to an adequate vascular bed.

* Trabalho realizado na Division of Thoracic and Cardiovascular Surgery, Department of Surgery, University of Virginia Health Sciences Center, Charlottesville, Virginia, USA.

1. Diretor do Serviço de Cirurgia Torácica do Hospital Universitário de Brasília, Brasília, DF.

2. Division of Thoracic and Cardiovascular Surgery, University of Virginia Health Sciences Center.
Este trabalho teve o suporte do CNPq - Conselho Nacional de Desenvolvimento Científico e Tecnológico, e suporte adicional do NIH e NRSA (EUA).

Endereço para correspondência - Nuno Ferreira de Lima, SHIS QI 15, Conj. 11, Cs.13 - 71635-310 - Brasília, DF. Tel. (061) 364-1587, fax (061) 347-4940.

Recebido para publicação em 18/9/98. Reapresentado em $21 / 1 / 99$. A provado, após revisão, em 5/3/99. 
Descritores - Transplante pulmonar. Transplante lobar experimental. Suino.

Key words - Lung transplantation. Lobar transplantation, experimental. Swine.

\section{INTRODUÇÃO}

O transplante pulmonar pediátrico tem sido aplicado de forma crescente e, como último recurso, no tratamento da fibrose pulmonar ou da doença vascular pulmonar em fase terminal|(1,2). 0 grau de sucesso é semelhante ao da experiência clínica dos transplantes pulmonares em adultos; contudo, a carência de enxertos pulmonares é bem mais grave no setor pediátrico, face à disparidade de tamanho entre receptor e potencial doador. A crítica falta de órgãos chega a elevar a taxa de mortalidade em lista de espera para até $48 \%{ }^{(3)}$. Com o objetivo de ampliar a oferta de órgãos, e assim reduzir 0 tempo em lista de espera, o transplante lobar de cadáver adulto ou de intervivos consanguíneos tem sido utilizado mais recentemente ${ }^{(4,5)}$.

Peculiar ao transplante pulmonar pediátrico é o fato de o receptor se encontrar em fase de crescimento. Por ser recente a experiência clínica, está ainda por ser demonstrado se o pulmão transplantado acompanha o aumento do volume torácico através de crescimento real ou se por expansão progressiva. 0 transplante lobar de doador adulto para receptor imaturo, além da denervação que impõe ao enxerto, submete o lobo maduro a um novo estímulo de crescimento, cujo resultado é desconhecido na prática clínica. Em estudos anteriores deste laboratório, o transplante lobar inferior e proporcionado de porco adulto para leitão teve função pulmonar adequada ao final do período de crescimento(6,7).

$\mathrm{Na}$ ausência de enxerto disponível e por necessidade de adequação de tamanho, crianças muito pequenas se tornam receptoras potenciais de segmento pulmonar ou lobo médio de doador adulto, configurando uma situação de transplante segmentar ou lobar particular. Este é um tipo de enxerto com reduzido leito vascular, que ao ser submetido ao crescente débito cardíaco do receptor em crescimento pode desenvolver hipertensão pulmonar subseqüente. Com o objetivo de testar essa hipótese, investigamos a utilização do lobo superior proporcionado e de leito vascular restrito transplantado em receptor em crescimento, num estudo experimentel em suínos. A avaliação funcional e morfométrica deste tipo de transplante foi realizada ao final do período de crescimento e comparada com enxertos pulmonares imaturos e enxertos lobares inferiores e desproporcionais, transplantados sob as mesmas condições.

\section{Material e MÉTOdOS}

O estudo foi realizado no laboratório de pesquisa do Departamento de Cirurgia Torácica e Cardiovascular da Uni-
Siglas e abreviaturas utilizadas neste trabalho

MHC - Complexo de histocompatibilidade maior

$\mathrm{CRF}$ - Capacidade residual funcional

C1 - Concentração inicial

C2 - Concentração final

V1 - Volume inicial

RVP - Resistência vascular pulmonar

PAP - Pressão da artéria pulmonar

PAE - Pressão do átrio esquerdo

DC - Débito cardíaco

versidade de Virginia, Charlottesville-EUA. Este laboratório desenvolveu especial familiaridade com o modelo suíno, como animal de experimentação, e o escolheu para esse tipo de estudo baseado no fato de que o desenvolvimento e a morfologia pulmonar desse animal se sobrepõem ao humano ${ }^{(8,9)}$. Do ponto de vista anatômico, os elementos do pedículo pulmonar esquerdo são similares aos do pulmão esquerdo no homem. Difere apenas pelo tamanho proporcionalmente muito menor do lobo superior esquerdo em relação ao lobo inferior esquerdo e pelo menor número de artérias para aquele lobo no porco. 0 porco apresenta boa tolerância à toracotomia, o que, ao lado de temperamento dócil, facilita a recuperação pós-operatória.

A espécie miniatura MHc-homozigótica de suínos, desenvolvida em laboratório através de cruzamento consanguíneo, foi utilizada neste estudo com o objetivo de reduzir as complicações pulmonares pós-transplante relacionadas ao binômio rejeição-infecção. 0 transplante entre animais da mesma linhagem, portanto com a mesma classe de alelos no complexo de histocompatibilidade maior ( $\mathrm{MHC}$ ), corresponde ao transplante entre irmãos gêmeos e dispensa o uso do esquema clássico de drogas anti-rejeição. Outra vantagem da utilização do porco miniatura está relacionada ao menor tamanho que atinge ao final do período da crescimento, neste caso específico de três meses, quando alcança a maturidade sexual, o que o torna de mais fácil manuseio comparativamente ao porco doméstico. 0 protocolo deste estudo foi revisado e aprovado pela Comissão para Uso de Animais de Experimentação da instituição. O s animais receberam tratamento humano de acordo com o A Guide for the Care and Use of Laboratory Animals, publicado pelo National Institute of Health $(\mathrm{NIH})$.

0 transplante lobar proporcionado, em que o lobo superior esquerdo de doador adulto foi de tamanho e peso semeIhante ao do pulmão esquerdo ressecado do leitão receptor, foi realizado em 4 leitões, constituindo o grupo de estudo I. O utro grupo de 5 leitões recebeu o transplante de lobo inferior esquerdo de doador adulto, com tamanho e peso duas vezes maior que o do pulmão esquerdo ressecado, formando o grupo experimental II. 0 transplante do pulmão esquerdo entre leitões da mesma idade foi realizado em 6 animais, 


\begin{tabular}{ccrrrr}
\hline \multicolumn{7}{c}{ TABELA 1 } \\
Características dos grupos de estudo \\
\hline G rupo & Enxerto & $\begin{array}{c}\text { Idade } \mathbf{R} \\
\text { (semanas) }\end{array}$ & $\begin{array}{c}\text { Peso } \mathbf{R} \\
\mathbf{( k g )}\end{array}$ & $\begin{array}{c}\text { Peso D } \\
(\mathbf{k g})\end{array}$ & $\begin{array}{c}\text { Relação D/R } \\
\text { (peso) }\end{array}$ \\
& & & & & \\
I & LSE & $8,8 \pm 0,8$ & $10,1 \pm 1,4$ & $43,7 \pm 6,3$ & 4,3 \\
II & LIE & $11,1 \pm 0,4$ & $9,8 \pm 1,3$ & $41,0 \pm 4,5$ & 4,3 \\
III & PE & $9,1 \pm 0,6$ & $9,1 \pm 0,6$ & $7,9 \pm 0,5$ & 0,87 \\
\hline
\end{tabular}

$\mathrm{R}=$ Receptor; $\mathrm{D}=\mathrm{D}$ oador; $\mathrm{LSE}=$ lobo superior esquerdo maduro proporcionado; $\mathrm{LIE}=$ lobo inferior esquerdo maduro desproporcionalmente maior; $\mathrm{PE}=$ pulmão esquerdo imaturo. Valores expressos em média \pm erro padrão.

constituindo o grupo experimental III, representando o tipo padrão de transplante pulmonar. A tabela 1 mostra as características dos grupos de estudo.

\section{Técnica operatória}

Os animais doadores e receptores foram deixados em jejum 12 horas antes da cirurgia. Os leitões receptores foram medicados com ácido acetilsalicílico $(100 \mathrm{mg})$ e ciclosporina (15 mg. $\left.\mathrm{kg}^{-1}\right)$, na tarde do dia que antecedeu o transplante. A anestesia foi induzida, em todos os animais, com xilazina $\left(1 \mathrm{mg} \cdot \mathrm{kg}^{-1}\right)$, tiletamina $\left(6 \mathrm{mg} \cdot \mathrm{kg}^{-1}\right)$ e sulfato de atropina $\left(0,02 \mathrm{mg} \mathrm{kg}^{-1}\right)$ por via intramuscular. A seguir procedeu-se à intubação e subseqüente ventilação com volume corrente de $15 \mathrm{ml} . \mathrm{kg}^{-1} \mathrm{com} 12$ a 15 incursões respiratórias por minuto. A punção venosa foi normalmente realizada numa orelha para administração de medicação e hidratação endovenosa. Azatioprina (1 mg. $\left.\mathrm{kg}^{-1}\right)$, solumedrol $(500 \mathrm{mg})$ e cefazolina (250 mg) foram administrados por via endovenosa imediatamente antes do início da cirurgia. O s animais doadores receberam metocurina $\left(0,2 \mathrm{mg} \cdot \mathrm{kg}^{-1}\right.$, IV $)$ e tiveram a anestesia mantida com $2,0 \%$ de halotano e ventilação com ar ambiente. Relaxantes musculares não foram utilizados nos recipientes, de modo a facilitar a extubação ao filnal do procedimento, e a anestesia foi-lhes mantida com $1,5 \%$ de isoflurano com ventilação a $100 \%$ de $\mathrm{FIO}_{2}$.

O s detalhes da retirada do enxerto pulmonar ou lobar, o preparo do mesmo e a técnica de transplante para o receptor foram descritos numa publicação anterior(10). Resumidamente, os animais doadores, posicionados em decúbito lateral direito, foram submetidos a toracotomia lateral esquerda com ressecção do quinto arco costal. A pós a administração de haparina venosa na dose de $200 \mathrm{U} . \mathrm{kg}^{-1}$ e de se proceder à infusão de um litro da solução de preservação Euro-Collins a $4 \stackrel{\circ}{ } \mathrm{C}$, os enxertos foram ressecados incorporando parte do lobo retrocardíaco e porção generosa do átrio esquerdo. 0 preparo dos enxertos a serem transplantados foi realizado numa mesa separada. Nos casos de transplante lobar, realizou-se a lobectomia inferior esquerda ou superior esquerda de forma anatômica, sendo que no transplante de lobo superior foram deixados $5 \mathrm{~mm}$ de abotão brônquico em torno da origem do brônquio lobar superior. Em todos os enxertos a coroa atrial para anastomose foi preservada incorporando a desembocadura das veias pulmores esquerdas e a veia pulmonar inferior direita.

Simultaneamente, os leitões receptores foram preparados para o transplante praticando a pneumonectomia esquerda após a administração de heparina venosa (200Ul.kg.-1), por clampeamento proximal da artéria pulmonar esquerda e do brônquio fonte esquerdo com o mínino de dissecção possível. As veias pulmonares esquerdas foram duplamente ligadas e seccionadas, uma vez que se utiliza o amplo apêndice atrial esquerdo para a anastomose venosa. Tanto o pulmão esquerdo nativo quanto o enxerto foram sempre submetidos à pesagem de rotina. As anastomoses foram realizadas pela ordem: brônquica com telescopagem e sutura contínua com fio absorbível 5-0 seguidas de desclampeamento imediato, arterial término-terminal com sutura contínua de fio absorvível 6-0, e atrial por clampeamento lateral do apêndice atrial esquerdo e sutura contínua com fio absorvível 5-0. As pinças vasculares foram removidas após a administração de uma dose complementar de heparina endovenosa (100Ul. $\mathrm{kg}^{-1}$ ). Os leitões foram mantidos com drenagem pleural até o dia seguinte e sob a mesma anestesia para a retirada do dreno foram obtidas as radiografias de tórax do primeiro dia de pós-operatório.

Os animais tiveram livre acesso a comida e água durante todo o período até ao estudo final. Á cido acetilsalicílico na dose de $325 \mathrm{mg} /$ dia foi administrado por 15 dias e em dias alternados, subseqüentemente. Cefalozina $250 \mathrm{mg}$ diariamente foi mantida até o sétimo dia de pós-operatório e a partir de então substituída por sulfametoxazol/ trimetoprim na dose de $800 \mathrm{mg}$ em dias alternados. A imunossupressão foi continuada usando o esquema tríplice (ciclosporina $15 \mathrm{mg}$. $\mathrm{kg}^{-1}$, azatioprina $1 \mathrm{mg} \cdot \mathrm{kg}^{-1}$ e solumedrol $500 \mathrm{mg}$, ao dia) até o sétimo dia, quando foi então mudada para apenas prednisona oral na dose de $2 \mathrm{mg} \cdot \mathrm{kg}^{-1}$ ao dia até o estudo final. Em caso de crises de rejeição, com diagnóstico presuntivo baseado em sinais clínicos como tosse, febre, taquipnéia, anorexia e letargia, poderia ser utilizada empiricamente pulsoterapia de esteróides (metilprednisolona $500 \mathrm{mg}$, IM 2 vezes ao dia). Radiografias de tórax de todos os animais foram obtidas ao final de um mês e imediatamente antes do estudo final.

\section{Estudo da função pulmonar}

A proximadamente três meses após o transplante, quando os animais atingiram a maturidade, vários parâmetros de função pulmonar e crescimento foram avaliados. Os animais, então na faixa de 26 a $28 \mathrm{~kg}$ de peso, foram pré-medicados com atropina $\left(0,02 \mathrm{mg} \cdot \mathrm{kg}^{-1}, \mathrm{IM}\right)$, tiletamina e xilazina, nas doses anteriormente citadas, e em seguida intubados. A ventilação mecânica foi estabelecida para um volume corrente de $15 \mathrm{ml} . \mathrm{kg}^{-1}$ e a freqüência respiratória de 15 a 20 incur- 
sões por minuto. Pentobarbital (10 mg. $\mathrm{kg}^{-1}$, IV) e metocurina $\left(0,2 \mathrm{mg} \cdot \mathrm{kg}^{-1}, \mathrm{IV}\right)$ foram administrados para anestesia e paralisação toda vez que necessário. A través de uma incisão cervical mediana, a artéria carótida primitiva, a veia jugular interna e a traquéia foram abordadas. A artéria carótida foi cateterizada para a medição contínua da pressão sistêmica e obtenção de amostras de sangue para gasometria. Por intermédio de um cateter de dupla entrada, introduzido na veia jugular direita, foi instalado o cateter de Swan-Ganz para mensurar a pressão pulmonar e débito cardíaco. O s transdutores sistêmico e pulmonar foram conectados à unidade de múltiplos canais, para monitorização contínua das pressões e cálculo do débito cardíaco (ES1000, Gould Inc, Cleveland, $\mathrm{OH}$ ). Via traqueotomia, o tubo orotraqueal foi substituído pelo traqueal $n-9$, de modo a facilitar a broncoscopia e ventilação seletiva. Foi utilizado broncoscópio flexível para avaliação das anastomoses brônquicas e orientação do bloqueio brônquico seletivo. A pós completados os estudos da função pulmonar, os animais foram sacrificados com uma dose letal de pentobarbital e o enxerto extraído para pesagem, análise macroscópica, histopatologia e determinação da relação peso úmido/ peso seco.

Para o estudo da mecânica pulmonar, os enxertos foram isolados in vivo utilizando o cateter balonado de Fogarty para oclusão do brônquio fonte direito e o próprio balonete do tubo traqueal para oclusão do brônquio do lobo superior direito. A fibrobroncoscopia permitiu identificar sempre a origem desse brônquio epiarterial na traquéia e orientou a oclusão seletiva e eficaz dos brônquios à direita. 0 fluxo aéreo e a pressão intrapulmonar foram medidos usando o pneumotacógrafo de Fleisch (O EM Corp, Richmond, VA) e dois transdutores diferenciais (MP45-1, Validyne Engineering Corp, Northridge, CA). O s sinais analógicos foram convertidos para digitais por um conversor, transferidos para um sistema de aquisição de dados (All Devices, San Rafael, CA) e armazenados em disquetes (Apple IIE, A pple Computers, Cupertino, CA ). Esses instrumentos foram calibrados previamente a cada estudo individual. Curvas de pressão-volume foram construídas para vários ciclos ventilatórios e em diferentes freqüências respiratórias, a partir das quais os cálculos da compliância dinâmica pulmonar e resistência dinâmica da via aérea puderam ser obtidos. Sob as mesmas circunstâncias de bloqueio brônquico à direita, a capacidade residual funcional (CRF) dos enxertos foi determinada usando o método de equilíbrio do hélio. Utilizando uma seringa graduada com uma concentração conhecida de hélio, os animais foram com ela ventilados a partir do final da expiração, até obter novo equilíbrio. Determinada a nova concentração de hélio na seringa, empregou-se a equação de Boyle para o cálculo final: $\mathrm{CRF}=((\mathrm{C} 1 . \mathrm{V} 1) / \mathrm{C} 2)-\mathrm{V} 1$, em que $\mathrm{C} 1$ é a concentração inicial de hélio, C2 é a concentração final de hélio e v1 é o volume inicial. Todas as medidas obtidas foram a média de três determinações consecutivas.
Em seguida procedeu-se à esternotomia mediana e abertura da pleura mediastinal direita. 0 pericárdio foi parcialmente aberto para verificar e auxiliar o posicionamento do cateter de Swan-Ganz na artéria pulmonar esquerda. O hilo direito foi então totalmente ocluído por uma pinça vascular de modo a excluir o pulmão nativo e aguardou-se um período de 15 minutos para obter a estabilização hemodinâmica. Sob ventilação com ar ambiente, foram tomadas três medidas do débito cardíaco pela técnica de termodiluição e obtida a pressão média na artéria pulmonar. A través da punção direta da auriculeta esquerda se obteve a pressão média do átrio esquerdo. A resistência vascular pulmonar (RVP, em dine.. $\mathrm{Cm}^{-5}$ ) dos enxertos foi calculada pela fórmula: RVP = PAP-PAE/DC.80, em que PAP é a pressão da artéria pulmonar em $\mathrm{mmHg}$, PAE é a pressão do átrio esquerdo em $\mathrm{mmHg}$, e $D C$ é o débito cardíaco em litros por minuto. Ao final do estudo da função pulmonar e sob ventilação com fração inspirada de oxigênio de 0,7 , amostras de sangue arterial foram colhidas para gasometria.

\section{Análise estatística}

Os resultados são apresentados sob a forma de média \pm erro padrão. A análise de variância (ANOVA) foi utilizada para comparar os dados obtidos no estudo dos três grupos de transplante. 0 valor de p igual ou menor que 0,05 foi considerado como estatisticamente significativo

\section{Resultados}

Embora o tempo de isquemia a que foram submetidos os enxertos lobares superiores (grupo I, $101 \pm 6,1$ minutos) e os lobares inferiores (grupo II, 110,2 $\pm 7,4$ minutos) tenha sido maior do que o dos enxertos do grupo do transplante pulmonar imaturo (grupo II, 90,3 \pm 3,8 minutos), em função do preparo adicional daqueles lobos, a diferença não foi estatísticamente diferente. Nesses três grupos de transplante pulmonar entre a espécie suína MHC-homozigótica, não se observaram quadros clínicos de rejeição. 0 período de crescimento variou de 11 a 12,3 semanas entre os grupos, não havendo diferença estatisticamente significativa nesse intervalo ou no ganho de peso dos animais (tabela 2). As radio-

\section{TABELA 2}

Período de crescimento e peso dos animais nos grupos de estudo

\begin{tabular}{lcrcc}
\hline Grupo & $\begin{array}{c}\text { Período de } \\
\text { crescimento } \\
\text { (semanas) }\end{array}$ & $\begin{array}{c}\text { Peso } \\
\text { inicial } \\
\mathbf{( k g )}\end{array}$ & $\begin{array}{c}\text { Peso } \\
\text { final } \\
\mathbf{( k g )}\end{array}$ & $\begin{array}{c}\text { Relação } \\
\text { Pi/Pf }\end{array}$ \\
I & $11,8 \pm 0,3$ & $10,1 \pm 1,4$ & $26,0 \pm 1,4$ & $2,8 \pm 0,2$ \\
II & $11,6 \pm 0,4$ & $9,8 \pm 1,3$ & $28,3 \pm 2,3$ & $3,0 \pm 0,3$ \\
III & $12,3 \pm 0,2$ & $9,1 \pm 0,6$ & $26,0 \pm 1,0$ & $2,9 \pm 0,1$ \\
\hline
\end{tabular}

$\mathrm{Pf}=$ peso final; $\mathrm{Pi}=$ peso inicial; O s valores representam a média \pm erro padrão. 


\begin{tabular}{|c|c|c|c|c|c|c|c|}
\hline \multicolumn{8}{|c|}{$\begin{array}{c}\text { TABELA } 3 \\
\text { Dados hemodinâmicos e da função pulmonar }\end{array}$} \\
\hline Grupo & $\begin{array}{c}\text { DC } \\
\left(\text { L. } \text { min }^{-1}\right)\end{array}$ & $\begin{array}{c}\text { PAP } \\
(\mathrm{mmH} g)\end{array}$ & $\begin{array}{c}\text { PAE } \\
(\mathrm{mmH} g)\end{array}$ & $\begin{array}{c}\text { RVP } \\
\text { (dine.s.cm-5) }\end{array}$ & $\begin{array}{c}\text { Cdin } \\
\left.\text { (ml.cm H } \mathrm{O}^{-1}\right)\end{array}$ & $\begin{array}{c}\text { Rva } \\
\left(\mathbf{c m} \cdot \mathrm{s}^{-1}\right)\end{array}$ & $\begin{array}{l}\mathrm{PaO}_{2}\left(\mathrm{FIO}_{2} 0,7\right) \\
(\mathrm{mmH} \mathrm{g})\end{array}$ \\
\hline I & $2,1 \pm 0,2$ & $51,8 \pm 2,1^{a}$ & $9,8 \pm 1,6$ & $1.605,9 \pm 117,5^{b}$ & $10,6 \pm 0,8$ & $27,5 \pm 2,6$ & $482,3 \pm 19,2$ \\
\hline II & $2,8 \pm 0,3$ & $40,4 \pm 2,5$ & $11,4 \pm 0,9$ & $857,6 \pm 133,5$ & $10,7 \pm 0,5$ & $19,8 \pm 1,9$ & $327,4 \pm 37,4$ \\
\hline III & $2,2 \pm 0,3$ & $34,8 \pm 1,5$ & $10,8 \pm 1,6$ & $930,9 \pm 117,2$ & $8,6 \pm 0,5$ & $31,8 \pm 2,4^{c}$ & $318,2 \pm 48,9$ \\
\hline
\end{tabular}

Valores expressos como média \pm erro padrão. DC = débito cardíaco; PAP = pressão da artéria pulmonar; PAE = pressão do átrio esquerdo; RVP = resistência vascular pulmonar; $\mathrm{C}$ din = compliância dinâmica; Rva = resistência da via aérea; $\mathrm{O}_{2}=$ pressão parcial do oxigênio no sangue arterial; $\mathrm{FIO}=$ fração inspirada de oxigênio. a $p=0,0003$ I versus II e I versus III. b $p=0,003$ I versus II e I versus III. c $p=0,01$ III versus II.

\begin{tabular}{ccccccc}
\hline \multicolumn{7}{c}{$\begin{array}{c}\text { TABELA 4 } \\
\text { Dados morfométricos }\end{array}$} \\
\hline Grupo & Relação I/E & $\begin{array}{c}\text { Peso inicial } \\
(\mathbf{g})\end{array}$ & $\begin{array}{c}\text { Peso final } \\
(\mathbf{g})\end{array}$ & Relação F/I & Relação U/S & $\begin{array}{c}\text { CRF } \\
\text { (mI) }\end{array}$ \\
& & & & & \\
I & 0,81 & $32,8 \pm 1,3$ & $92,8 \pm 7,0$ & 2,8 & 4,4 & $250,2 \pm 15,2$ \\
II & 1,93 & $72,4 \pm 6,8$ & $111,3 \pm 8,6$ & $1,5^{\text {a }}$ & 4,7 & $244,0 \pm 11,3$ \\
III & 0,85 & $34,6 \pm 1,5$ & $107,8 \pm 5,9$ & 3,1 & 4,8 & $200,5 \pm 23,6$ \\
\hline
\end{tabular}

Valores são média \pm erro padrão. $\mathrm{I} / \mathrm{E}=$ peso do implante sobre peso do explante. F/I = peso final sobre peso inicial. $\mathrm{U} / \mathrm{S}=$ peso úmido sobre peso seco. $\mathrm{CRF}=$ capacidade residual funcional. a $\mathrm{p}=0,001 \mathrm{II}$ versus I, e II versus III.

grafias de controle 1 mês e 3 meses após o transplante mostram boa transparência do parênquima pulmonar, sem condensações ou hiperlucências, em todos os animais dos três grupos.

Os resultados do estudo da função pulmonar dos grupos de estudo e experimentais estão expressos na tabela 3. A comparação da função pulmonar dos grupos de transplante em conjunto mostrou que o grupo do transplante lobar superior e proporcionado (grupo I) teve níveis pressóricos na artéria pulmonar e resistência vascular pulmonar significativamente mais elevados do que os grupos II e III ( $p=0,0003$ e $p=0,003$, respectivamente). 0 grupo II apresentou menor resistência dinâmica da via aérea comparativamente aos do is outros grupos, atingindo significância estatística em relação ao grupo III $(p=0,01)$. A capacidade de oxigenação foi equivalente em todos os grupos.

Os dados morfométricos, cuja análise permite inferir o potencial de crescimento do enxerto pulmonar ao fim do período de crescimento dos animais transplantados, estão representados na tabela 4 . 0 enxerto lobar superior maduro e proporcionado, implantado nos leitões do grupo I, foi um pouco menor que o pulmão nativo explantado e aumentou cerca de $180 \%$ do peso inicial. O grupo II, do transplante de lobo inferior maduro e desproporcionado, recebeu um enxerto aproximadamente duas vezes maior do que o pulmão nativo explantado; o lobo, por sua vez, aumentou $50 \%$ de peso até ao final do estudo. 0 grupo III, do transplante pulmonar imaturo, recebeu um enxerto um pouco menor que 0 pulmão nativo e veio a aumentar o peso em torno de $210 \%$ até ao final do período de crescimento. Não houve diferenças estatisticamente significativas entre os três grupos quanto ao peso final do enxerto e capacidade residual funcional. A capacidade residual funcional tem aqui conotação de volume do enxerto. A relação entre peso úmido e peso seco foi semelhante entre os dois grupos.

\section{DISCUSSÃO}

Perante a situação de falta de doador adequado quanto à similaridade de tamanho e idade, as crianças menores terão apenas como último recurso a captação de segmentos pulmonares ou de lobo médio de adulto consanguíneo, em compatibilidade com a diminuta cavidade pleural. A grande disparidade entre doador e receptor impõe um enxerto que, embora proporcional, mas de leito vascular restrito, poderá ser clinicamente inadequado. A utilização de pulmões pequenos em relação ao receptor foi responsabilizada pela excessiva pressão pulmonar intra-operatória, e subseqüente morte hospitalar, numa pequena série de transplantes pulmonares pediátricos ${ }^{(11)}$. Numa outra série de seis pacientes receptores de transplante lobar, uma criança de 4 anos de idade portadora de síndrome de Eisenmenger teve evolução semelhante ao receber o lobo médio de seu pai e ter a patologia cardíaca corrigida(12). Esse foi o único óbito perioperatório da série, igualmente por hipertensão pulmonar persistente e edema pulmonar maciço em decorrência da micro- 
vasculatura inadequada do enxerto. Embora esses casos retratem uma situação aguda pós-implante, na qual a própria solução de preservação hiperpotassêmica (Euro-Collins) pode afetar a função do enxerto em caso de hiperfluxo(13), o dado comum de restrição da vasculatura do enxerto representa um importante obstáculo ao uso desse tipo de transplante.

0 transplante lobar proporcional, que neste modelo experimental se constituiu no lobo superior esquerdo de leito vascular restrito, comparativamente ao enxerto dos outros grupos, desenvolveu hipertensão pulmonar quando submetido ao débito cardíaco total por ocasião do estudo final. Essa disfunção a longo termo e após o período de crescimento somático tem implicações fundamentais quanto ao sucesso tardio desse tipo de transplante. No presente estudo experimental, por ser um modelo crônico de sobrevivência e crescimento, a função pulmonar do enxerto não foi testada logo após o implante. É possivel que já existisse aumento da resistência pulmonar imediatamente após o transplante, em comparação com os outros tipos de enxerto, que não se manifestaria clinica e radiologicamente na forma de edema pulmonar porque o pulmão contralateral acomodaria a subtotalidade do débito cardíaco. Por outro lado, há evidências indiretas de adequado fluxo pulmonar para o enxerto lobar proporcionado, em função do achado de anastomoses vasculares amplamente pérvias ao estudo final, presença de sombras vasculares nas radiografias de controle e aumento de tamanho do enxerto ao longo do período de crescimento.

A análise dos dados morfométricos mostra que o enxerto lobar superior maduro e proporcionado atingiu peso final que estatisticamente não foi diferente do dos outros tipos de enxerto e representou aumento de cerca de três vezes seu peso inicial. Esses dados, portanto, ao lado da evolução radiográfica, da medida da capacidade residual funcional, da mecânica ventilatória e pelo igual conteúdo de água total, sugerem que o lobo maduro proporcionado foi capaz de crescer quando implantado no animal em crescimento. Os achados hemodinâmicos do estudo final sugerem que, sendo a matriz vascular do enxerto restrita, o crescimento do enxerto pode não ser capaz de promover o aumento da compliância vascular de modo a se capacitar para débito cardíaco aumentado do animal adulto. Estudos sobre o crescimento pulmonar compensatório em animais imaturos submetidos a pneumonectomia demonstram que 0 aumento de peso do pulmão remanescente ocorre em virtude da proliferação celular e do estroma, numa tentativa de reconstituir a totalidade do parênquima pulmonar ${ }^{(14,15)}$. N esses estudos, o cálculo do ADN (ácido desoxirribonucléico) total, a quantidade de proteína, o número e a superfície alveolar total aumentaram consideravelmente ao lado da elevação de peso e volume pulmonar. Vários parecem ser os mecanismos implicados no estímulo ao crescimento pulmonar pós-pneumonectomia, tais como o estiramento pulmonar ${ }^{(16)}$, fatores de crescimento específicos para o pulmão(17,18), e o fluxo pulmonar ${ }^{(19,20)}$. Contudo, esses estudos não estabeleceram um paralelo entre crescimento pulmonar e aumento da capacidade funcional, no animal em crescimento. No grupo singular do transplante lobar maduro e proporcionado, ficou demonstrado que 0 enxerto foi capaz de crescer, embora sem ampliar o leito vascular, de modo a capacitá-lo para animal adulto.

Ao final do período de crescimento, o enxerto lobar maduro desproporcional (grupo II) apresentou função pulmonar normal e equivalente ao enxerto pulmonar imaturo do grupo III. A única diferença esteve relacionada à resistência da via aérea, que foi expressivamente menor no grupo II comparativamente aos outros dois grupos, atingindo significância estatística em relação ao grupo III. Essa redução relativa da resistência da via aérea no grupo II pode ser interpretada como um sinal indireto de subseqüente aumento de calibre da árvore brônquica do completamente desenvolvido lobo inferior maduro, já desproporcionalmente maior quando do transplante no animal em crescimento. Esse tipo de enxerto, que foi facilmente acomodado na bem menor cavidade pleural do receptor neste modelo experimental, pelo mecanismo que denominamos de colapso periférico acomodativo, pode ser uma boa alternativa para a expansão das fontes doadoras de enxerto pulmonar(21).

O s maiores entraves à ampla utilização do transplante de pulmão no tratamento da insuficiência pulmonar em estágio final, causada por grande variedade de doenças pulmonares, estão relacionados ao desenvolvimento de bronquiolite obliterante e à escassez de doadores ${ }^{(22)}$. 0 transplante pulmonar unilateral tem tido aplicabilidade crescente com o objetivo de ampliar a oferta, a partir da restrita fonte doadora. Essa situação, que é ainda mais crítica na área pediátrica em função da disparidade de tamanho entre o receptor e os órgãos disponíveis, estimulou o início da utilização de lobos pulmonares de adultos, paralelamente ao maior uso do transplante pulmonar unilateral. Entretanto, por ser muito recente, não se sabe da evolução a longo prazo desses tipos de enxertos, quanto à capacidade de crescimento e adaptação a demanda funcional crescente, ao longo da expectativa de vida do receptor pediátrico(23). Este estudo experimental permite inferir que, embora passível de crescimento, o enxerto lobar maduro necessita ter um leito vascular adequado, para que seja funcionalmente competente no receptor quando adulto. Perante situações de grande disparidade entre receptor e doador, no transplante pulmonar pediátrico, a proporcionalidade de enxerto lobar ao hemitórax do receptor deverá ser secundária a um amplo leito vascular pulmonar.

\section{REFERÊNCIAS}

1. Cohen RG, Barr ML, Starnes VA. Pediatric lung transplantation. Seminars Pediatr Surg 1993;2:279-288.

2. Noyes BE, Kurland G, Orenstein DM, Fricker FJ , Armitage J M. Experience with pediatric lung transplantation. J Pediatr 1994;124:261268 
3. Whitehead BF, De Leval MR. Paediatric lung transplantation: the agony and the ecstasy. Thorax 1994;49:437-439.

4. Starnes VA, Lewiston NJ, Luikart H, Theodore J, Stinson EB, Shumway NE. Current trends in lung trasplantation - Lobar transplantation and expanded use of single lungs. J Thorac Cardiovasc Surg 1992; 104:1060-1066.

5. Cohen RG, Barr ML, Schenkel FA, et al. Living-related donor lobectomy for bilateral lobar transplantation in patients with cystic fibrosis. Ann Thorac Surg 1994;57:1423-1428.

6. Kern J A, Tribble CG, Chan BBK, Flanagan TL, Kron IL. Reduced-size porcine lung transplantation: long term studies of pulmonary vascular resistance. Ann Thorac Surg 1992;53:583-589.

7. Kern J A, Tribble CG, Zografakis J G, Cassada DC, Chan BBK, Kron IL. A nalysis of airway function of immature whole lung transplants versus mature lobar transplants. Ann Thorac Surg 1994;57:10891094.

8. Winkler GC, Cheville NF. The neonatal porcine lung: ultrastructural morphology and postnatal development of the terminal airway and alveolar region. A nat Rec 1984;210:303-313.

9. Winkler GC, Cheville NF. Morphometry of postnatal development in the porcine lung. Anat Rec 1985;211:427-433.

10. DeLima NF, Binns OAR, Buchanan SA, Tribble CG, Kron IL. Experimental lung transplantation: a successful porcine survival model. $\mathrm{S}$ Am J Thorac Surg (in press).

11. Lillehei CW, Shamberger RC, Mayer JE, et al. Size disparity in pediatric lung transplantation. J Pediatr Surg 1994;29:1152-1156.

12. Starns VA, Barr LM, Cohen RG. Lobar transplantation - Indications, technique, and outcome. J Thorac Cardiovasc Surg 1994;108:403411.
13. DeLima NF, Binns OAR, Buchanan SA, et al. Euro-Collins solution exacerbates lung injury in the setting of high-flow reperfusion. J Thorac Cardiovasc Surg 1996;112:111-116.

14. Doerschuk CM, Sekhon HS. Pulmonary blood volume and edema in postpneumonectomy lung growth in rats. J Appl Physiol 1990;69: 1178-1182.

15. Sekhon HS, Thurlbeck WM. A comparative study of postpneumonectomy compensatory lung response in growing male and female rats. J Appl Physiol 1992;73:446-451.

16. Liu M, Skinner SJ M, Xu J, Han RNN, Transwell AK, Post M. Stimulation of fetal rat lung cell proliferation in vitro by mechanical stretch. Am J Physiol 1992;263:L376-383.

17. Faridy EE, Sanii MR, Thliveris J A. Influence of maternal pneumonectomy on fetal lung growth. Respir Physiol 1988;72:195-210.

18. Dubaybo BA, Bayasi G, Rubeiz GJ . Changes in tumor necrosis factor in postpneumonectomy lung growth. J Thorac Cardiovasc Surg 1995; 110:396-404.

19. Simnett J D. Stimulation of cell division following unilateral collapse of the lung. A nat Rec 1974;180:681-686.

20. MCB ride JT, Kirchner KK, Russ G, Finkelstein J. Role of pulmonary blood flow in postpneumonectomy lung growth. J Appl Physiol 1992; 73:1448-1451.

21. DeLima, NF. Transplante lobar desproporcional: um modelo experimental de transplante pulmonar em suínos. Tese de Doutorado. Universidade Federal do Rio Grande do Sul, 1996.

22. Davis RD, Pasque MK. Pulmonary transplantation. Ann Surg 1995; 221:14-28.

23. Report of the ATS workshop on lung transplantation. Am Respir Dis $1993 ; 147: 772-776$ 